\title{
Extraction, Characterisation and Industrial Applications of Sesamum indicum Seed Oil
}

\section{Chinweuba $\mathrm{AJ}^{*}$ and Chendo MN}

Department of Chemistry, Anambra State University, Nigeria

\begin{abstract}
Oil was extracted from ground Sesamum indicum seeds by solvent extraction method using Soxhlet extractor and $\mathrm{n}$-hexane as the solvent. The percentage oil yield on weight of the dried seeds was $32 \%$. The oil quality parameters were accessed in terms of acid value, free fatty acid value, saponification value, iodine number and peroxide value. The results obtained showed the oil to be non drying oil with iodine value of $76.56 \mathrm{~g} / 100 \mathrm{~g}$ and could be used for skin cream production. The acid and free fatty acid values of Sesamum indicum seed oil showed that the oil would not require any purification before use. The saponification value of $55.90 \mathrm{mg} / \mathrm{g}$ suggested that the oil could be used for soap production. The results confirmed that the oil could also be used for grease production, alkyd resin and paints.
\end{abstract}

Keywords: Seed oil; Sesamum indicum; Industrial applications

\section{Introduction}

Sesamum indicum also called Sesame in English is among the oldest cultivated crop and its origin has been traced to Africa. History had it that Africa slaves brought benne seeds to America where the name changed from benne to sesame. At about 4000 years ago, Sesamum indicum seeds were one of the highest prized seeds oil in Assyria according to Ref. [1]. Sesame is an annual self pollinating plant growing up to $1.20 \mathrm{~m}$ tall [2]. The leaves are usually up to $4 \mathrm{~cm}$ long and $5 \mathrm{~cm}$ broad, the flowers are usually yellow in colour with four lobed mouths. However, the colour of the flowers may vary from pink to white [3]. The flowers are borne on short glandular pedicles and are produced at each leaf axils and the lower flowers usually bloom 3 months after planting [4]. The length of its fruit is between $2-8 \mathrm{~cm}$, width between $0.5-2.0 \mathrm{~cm}$ and it is in capsule form but the seeds are very small about $3 \mathrm{~mm}$ in length and $2 \mathrm{~mm}$ width [3]. Sesamum indicum has different usages in different countries. Sesamum lignans have antioxidant and health promoting activities [5]. In Europe sesame seed oil is often used as a substitute for Olive oil. In Japan apart from being used in salad it is used in treating cough, for treating cancer in Germany, for treating cold in Venezuela, for treating constipation, impotency, malaria, diarrhea and sore in China. Indians use it in treating tumour [6]. Sesame oil has been used as a solvent for intramuscular injections for several years [7]. Chinese people have used the oil as a remedy for toothaches and gum diseases while Indians had used the oil as an antibacterial for treatment of nasal mucosa dryness [8]. The seeds shells has been reported to be very rich in fibres that the roasted seeds are used in bakery and in production of candies in Greece and some parts of Africa. Refined Sesame seed oils have longer shelf life with excellent antioxidant properties, with improved flavour and taste that has attracted the food industries in USA [9]. Dark in 1998 reported that Sesame seed oil had served as a solvent in drugs making, margarine and skin softener productions. In Agriculture, Sesame meal according to experts is superb feed for livestock and poultry. This paper reports the extraction, characterisation and Industrial applications of Sesamum indicum seed oil.

\section{Methods}

Sesame seeds were picked from a small bush in Amansea in Anambra State, Nigeria and were washed. The seeds were sun dried for 5 days and were ground to powdered form in a mortar.

\section{Oils extraction and characterisation}

Oils from sesame seeds were extracted by Solvent extraction method using Soxhlet extractor with $\mathrm{n}$-hexane as solvent. After extraction, excess solvent in the extracted oil was distilled off at $80^{\circ} \mathrm{C}$. The percentage oil yield was calculated from the ratio of mass of oil to the mass of the ground seeds used for the extraction. The extracted oil was characterised by determination of its free fatty acid and acid values by methods described by Wieldemann The iodine value, saponification value, peroxide value, colour, texture, solubility and $\mathrm{pH}$ value were determined by standard procedures described by the American Oils Chemists Society AOCS Official methods. The specific gravity of the oil was determined by methods described by Ref. [10].

\section{Solid and liquid soaps formulations}

$50 \%$ of Sodium hydroxide was added to $14.25 \%$ of Sesame seed oil in $35.50 \%$ water and $0.02 \%$ sodium silicate. The mixture was boiled under reflux until solid soap was formed. The liquid soap was produced from Sesamum indicum seed oil by saponification of $30 \%$ of the oil with $8 \%$ potassium hydroxide, $58,8 \%$ water and $3.2 \%$ alcohol or formaldehyde [11]

\section{Alkyd resin formulation}

Alkyd resin was produced from Sesamum indicum seed oil by alcoholysis method. Sesame seed oil (23.05\%), glycerol (33.85\%) and Phthalic anhydride (43.00\%) were refluxed under carbon IV oxide with continuous stirring at $240^{\circ} \mathrm{C}$ until alkyd resin was formed [12].

\section{Grease formulation}

Production of grease from Sesamum indicum seed oil was done by cold saponification method as described by [13].

\section{Paint formulation}

The resin formed from Sesamum indicum seed oil 34.1\%, mineral oil $22.0 \%$, thymol $0.2 \%$, titanium oxide / calcium carbonate $22.1 \%$ and turpentine $20.0 \%$ were mixed and stirred continuously to form paint.

*Corresponding author: Chinweuba AJ, Department of Chemistry, Anambra State University, Nigeria, Tel: 2348035088532; E-mail: aryzrazy@yahoo.com

Received March 29, 2017; Accepted April 11, 2017; Published April 14, 2017

Citation: Chinweuba AJ, Chendo MN (2017) Extraction, Characterisation and Industrial Applications of Sesamum indicum Seed Oil. Mod Chem Appl 5: 216. doi: 10.4172/2329-6798.1000216

Copyright: @ 2017 Chinweuba AJ, et al. This is an open-access article distributed under the terms of the Creative Commons Attribution License, which permits unrestricted use, distribution, and reproduction in any medium, provided the original author and source are credited. 


\section{Formulation of body cream}

$4.75 \mathrm{~g}$ Sesame indicum seed oil was mixed with $2.0 \mathrm{~g}$ of emulsifying wax, $1.0 \mathrm{~g}$ of stearic acid and $0.7 \mathrm{~g}$ cetyl alcohol. The mixture was heated to $70^{\circ} \mathrm{C}$ and a mixture of $15 \mathrm{~g}$ water, $1.70 \mathrm{~g}$ glycerine and $5.0 \mathrm{~g}$ sodium stearate was added with continuous stirring. $0.8 \mathrm{~g}$ of Sodium benzoate, $0.2 \mathrm{~g}$ methyl paraben, and $0.5 \mathrm{ml}$ of propylene glycol were added and stirred to form cream [13].

\section{Results and Discussion}

The physiochemical properties of Sesamum indicum seed oil are shown in Table 1 above. The percentage oil yield of 32 was higher than some known oils used in industries examples, Sunflower 25$28 \%$, Cotton $18-28 \%$, and Soya bean 11-25\%. Sesamum indicum seed oil had iodine value of $76.56 \mathrm{~g} / 100 \mathrm{~g}$ which placed the oil in the class of non drying oil, appropriate for industrial production of, liquid and solid soaps, alkyd resin, grease, body cream and paints. The low saponification value of 25.95 suggested that the oil could be used for soap production. The iodine value of the oil placed it as a non drying oil which confirmed that it could be utilized in body cream and alkyd resin productions. Peroxide value of $4.45 \mathrm{meq} / \mathrm{kg}$ showed that the degree of oxidation in the oil was low, which could be attributed to the nutty flavour of the oil. Oils with high peroxide values are known to have awful smell. Acid value of oil gives indication of its freshness and

\begin{tabular}{|c|c|}
\hline Properties & Values \\
\hline Colour & Light yellow \\
\hline Texture & Viscous \\
\hline Solubility & Immiscible with water \\
\hline Physical state at room temperature $\left({ }^{\circ} \mathrm{C}\right)$ & Liquid \\
\hline Odour & Nutty flavour \\
\hline Oil yield $(\mathrm{w} / \mathrm{w} \%)$ & 32.00 \\
\hline Acid value $(\mathrm{mg} \mathrm{NaOH} / \mathrm{g})$ & 0.94 \\
\hline Free Fatty acid value $(\mathrm{mg} \mathrm{NaOH} / \mathrm{g})$ & 0.47 \\
\hline Iodine value $\mathrm{g} / 100 \mathrm{~g}$ & 76.56 \\
\hline Saponification value $\mathrm{mg} / \mathrm{g}$ & 25.90 \\
\hline pH value & 6.70 \\
\hline Peroxide value $(\mathrm{meq} / \mathrm{kg})$ & 4.45 \\
\hline Specific gravity & 0.82 \\
\hline
\end{tabular}

Table 1: Physical and chemical characteristics of Sesamum indicum seed oil. edibility. The low values of acid and free fatty of Sesamum indicum seed oil also suggested that the oil would have long shelf life, thus suitable for industrial uses [13].

\section{Conclusion}

All products made from Sesamum indicum seed oil compared satisfactorily with commercially available ones in the local market; thus, the oil could be utilized for Industrial production of soaps, body cream, grease, alkyd resin and paints.

\section{References}

1. Oplinger ES, Putnam DH, Kaminski AR, Hanson CV (1990) Sesame Corn Agronomy. Field Crops Manual.

2. Kato MJ, Chu A, Davin BL, Lewis NG (1998) Biosynthesis of antioxidant lignans in Sesamum indicum seeds. Phytochemistry 47: 583-591.

3. Beckstrom SM, Duke JA, Wain KK (1994) The phytochemical database.

4. Tyler VE, Brady LE, Robbers JE (1976) Lipids. In: Lea F (ed.), Pharmacognosy. Philadelphia, USA, pp: 121-122.

5. Johnson J, Bratt BM, Michel BO, Glennow C (2001) Pure sesame oil vs isotonic sodium chloride solution as treatment for dry mucosa. Arch Oto Laryngol Head Neck Surg 127: 1353-1356.

6. Williams KA (1996) Oils Fats and Fatty Foods. Elsevier, New York, USA, pp 88-122.

7. Ajiwe VIE, Okeke CA, Nnabuike B (1997) Applications of Oils extracted from African star apple (Chrysophyllum africanum), Horse eye bean (Mucana sloanei) and African Pear (Dacryodes edulis) seeds. Bioresources Technology 59: 259-261.

8. AOCS Official Methods (1960) Sampling and analysis of commercial Fats and Oil. AOCS, Washington, USA, pp: 801-855.

9. Morris JB (2002) Food Industrial, nutraceutical and pharmaceutical uses of sesame genetic resources, pp: 153-156.

10. Dark G (1998) Online Medical Dictionary.

11. Lambert J, Muir JA (1968) Practical Chemistry. Heinemann Education Books London, UK, pp: 315-318.

12. Wieldemann LH (1981) Degumming, refining and bleaching of Soya bean oil. JAOCS 58: 159-165.

13. Chinweuba AJ (2013) Characterisation and Industrial applications of oils extracted from Vitex doniana and Citrullus vulgaris seeds. International Journal of Advance Research 2: 1-4. 